\title{
Forensic examination of handwriting and thumb impression-A case study
}

\author{
Reeta R Gupta ${ }^{1 *}$, Harinder Prasad ${ }^{2}$ \\ ${ }^{1,2}$ Senior Scientific Officer Document Divisionentral Forensic Science Laboratory (CFSL) Central Bureau of Investigation (CBI) New \\ Delhi, India \\ *Corresponding Author: Reeta R Gupta \\ Email: reetacbi@gmail.com
}

\begin{abstract}
Handwriting Science and Finger Print examination both are significant branches of Forensic Science. This article illustrates one of the important cases related to cheating by impersonation in constable recruitment examination. The case was submitted in Central Forensic Science Laboratory CBI, New Delhi for examination and opinion on handwritings as well as finger thumb impressions with detailed questionnaires. Inter see examination and comparison of questioned document with standard document reveals that both the sets were consistent in detailed characteristic features and execution of strokes in construction of letter and their combination in words. The authorship of questioned documents was matched with the supplied specimen documents. Also, the questioned thumb impressions were compared with the standard thumb impression and were found consistent between both the sets. The case was examined thoroughly by applying the principle of handwriting science and finger thumb impression. The case was successfully solved on the basis of forensic analysis of handwritings and finger thumb impressions. The scientific evidence was produced during court testimony by the experts and opinion was accepted in the court of law and finally the suspected person was convicted.
\end{abstract}

Keywords: Questioned document examination, Thumb impression, Forensic examination.

\section{Introduction}

Questioned document examination and finger print examination both are significant branches of forensic science. according to principle of handwriting science no two person can write same with similar writing characteristics and same person cannot write exactly same twice. Fingerprints are unique in nature as every individual has his/her fingerprint to provide its own identity. The finger contains a complicated structure of ridges with sweat glands at regular intervals. The patterns remain as such of any individual from birth to death and do not change with growth except size. Questioned document examination of disputed document is bases on the comparison and analysis of significant individual characteristics features identification in between questioned and standard handwriting content. The various cases related with fraud and forgery and falsification of documents has come in knowledge in daily life which affects everyone in society. The objective of this article is to illustrate one of the most important cases related to cheating by impersonation in constable recruitment examination. The forensic analysis of document was carried out by established fundamental methods of handwriting science and Finger Print and the case opinion was furnished. Inter see examination and comparison of questioned document with standard document reveals that both the sets were consistent in detailed characteristic features and execution of strokes in construction of letter and their combination in words. The authorship of questioned documents was fixed with the supplied standard documents and the questioned thumb impressions were compared with the standard thumb impression and found consistent between both the sets of two suspects. This paper demonstrated the example of one of the important scam case in which the evidence was produced in the form of opinion and demonstrated by adaptation of two scientific methodologies questioned documents examination and finger print examination of forensic science. The ability to produce scientific evidences through application of scientific methodology by the forensic experts is only possible in this forensic science field to favor criminal justice system.

\section{Brief Case History}

The case was submitted for examination by the Superintendent of Police, CBI in Central Forensic Science Laboratory CBI New Delhi for forensic examination and opinion on handwriting as well as finger thumb impression with detailed questionnaires enclosing document bearing two sets of Questioned OMR sheets on which the questioned document for handwriting and thumb impressions were marked. Questioned handwriting, Specimen handwriting, Questioned thumb impression for examination and comparison with Specimen left and right thumb impressions slips were submitted for expert opinion thereon in connection with constable recruitment scam. Briefly the case is explained that this is one of the important scam case related to cheating by personation in constable recruitment examination in Madhya Pradesh. In compliance of the order of Hon'ble Supreme Court, the case RC was registered in CBI New Delhi u/s 419 \& 420 and section 3 of MP Recognized Examination Act against the accused involved.

\section{Detail of Case Examination}

The illustrated case was examined in Central Forensic Science Laboratory New Delhi in which two original OMR sheet bearing the Questioned, writings marked Q-3 shown in Fig. 1 and Questioned thumb impressions marked Q-1 shown in Fig. 13 of suspect-A and the Questioned writings marked Q-8 shown in Figure-2 and Questioned thumb 
impressions marked Q-6 shown in Fig. 14 of suspect-B were submitted along with the Specimen handwriting marked S-1 to S-4 shown in Figure-3 to Figure-6 and specimen thumb impressions on slip of suspect A shown in Figure-15 and the Specimen handwriting marked S-1A to S-6A shown in Figure-7 to Fig. 12 and specimen thumb impressions on slip of suspect-B shown in Figure-16. The Questioned handwriting marked Q-3 \& Specimen hand writing marked S-1 to S-4 of suspect A and Questioned handwriting marked Q-8 \& Specimen handwriting marked S-1A to S-6A of suspect B were compared and scientifically examined by applying the principle of handwriting science in order to identify the writing characteristic features to fix the authorship. Similarly Questioned thumb impression marked Q-1 of suspect-A and Q-6 of suspect-B was subjected to thorough careful scientific examination and compared with the corresponding supplied specimen thumb impression of suspect A and suspect-B applying the principle finger print examination. Visual and optical examination of Questioned documents including both handwriting \& thumb impressions and its comparison with corresponding Specimen handwriting and thumb impression revealed that there were significant similarity in the questioned document with Specimen document of both suspect A and Suspect B.The questioned writings of suspect A and Suspect B including questioned thumb impression marked Q-1 of suspect-A and Q-6 of suspect-B was subjected to thorough careful scientific examination and compared with the corresponding supplied specimen writings of suspect $A$ and suspect-B including thumb impressions of suspect-A and suspect-B.

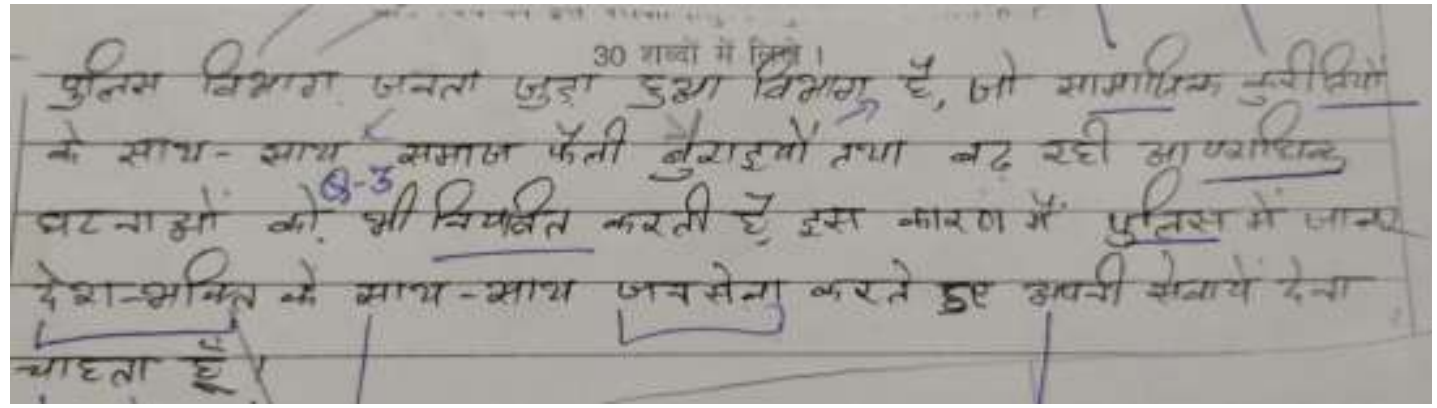

Fig. 1: Questioned Handwriting on OMR sheet marked Q-3 of Suspect A

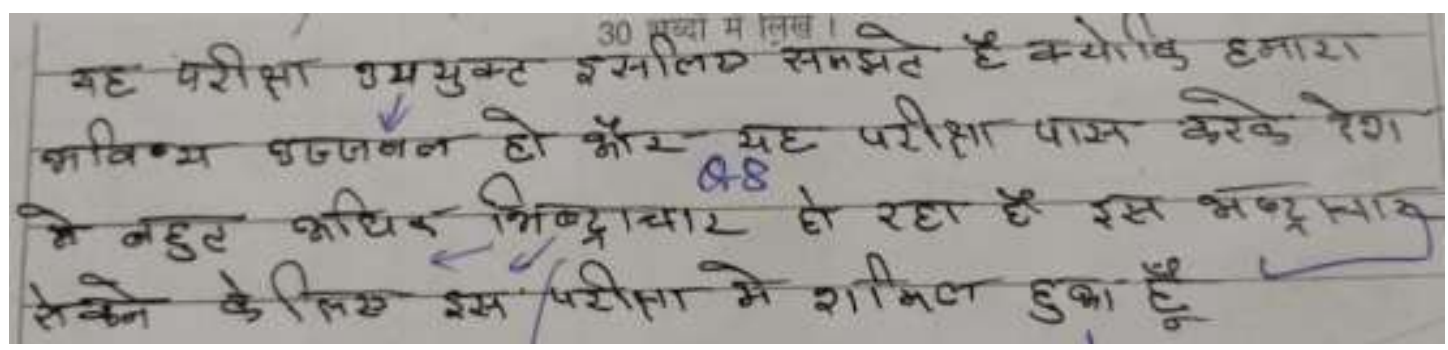

Fig. 2: Questioned Handwriting on OMR sheet marked Q-8 of Suspect B

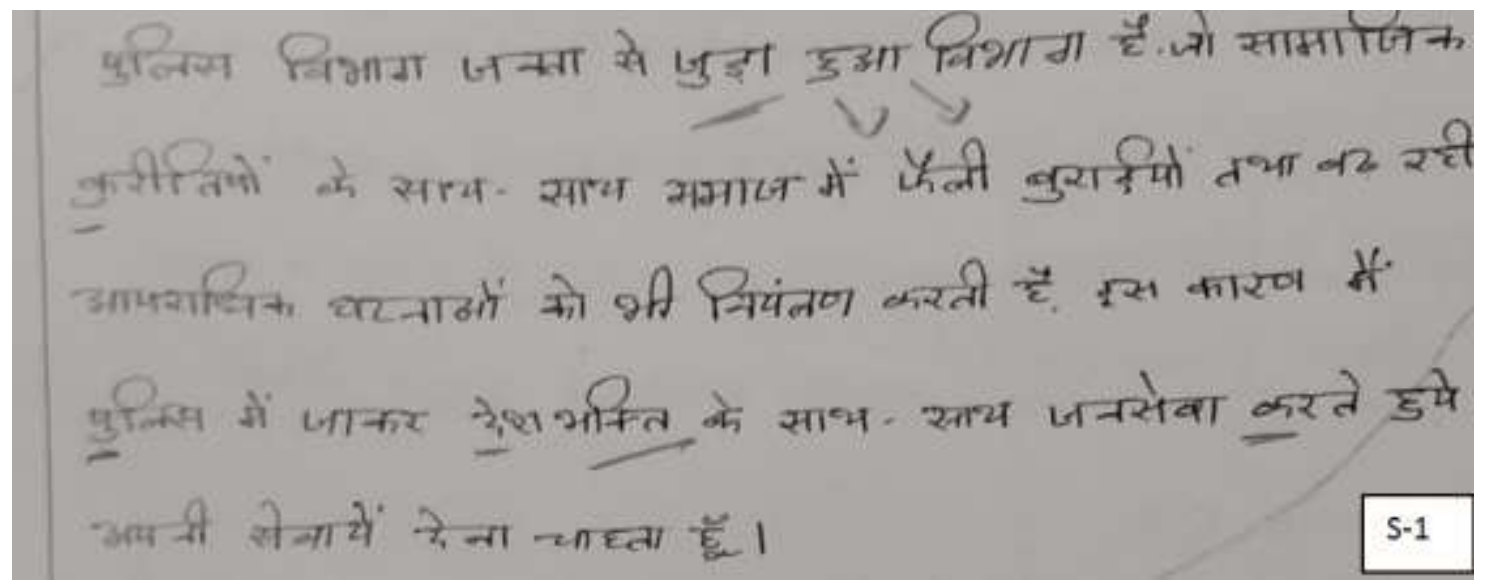

Fig. 3: Specimen Handwriting of Suspect-A marked as S-1 


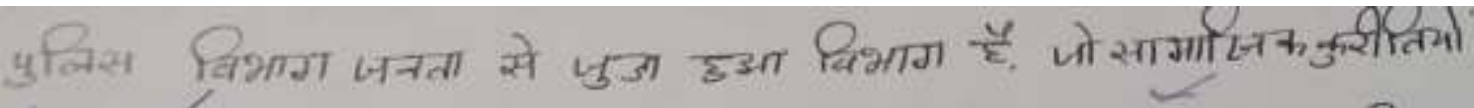
की साध-साय समाज में फैनी बुराहयों तथा बर रही आयाधिक परनाओं को भी नियंनका करती है जस कारण में पुलिस में जा कर 2,91 अक्ति के साथ- साथ जनसेना करते हुये अपनी सेनायें देना चाहता है।

Fig. 4: Specimen Handwriting of Suspect-A marked as S-2

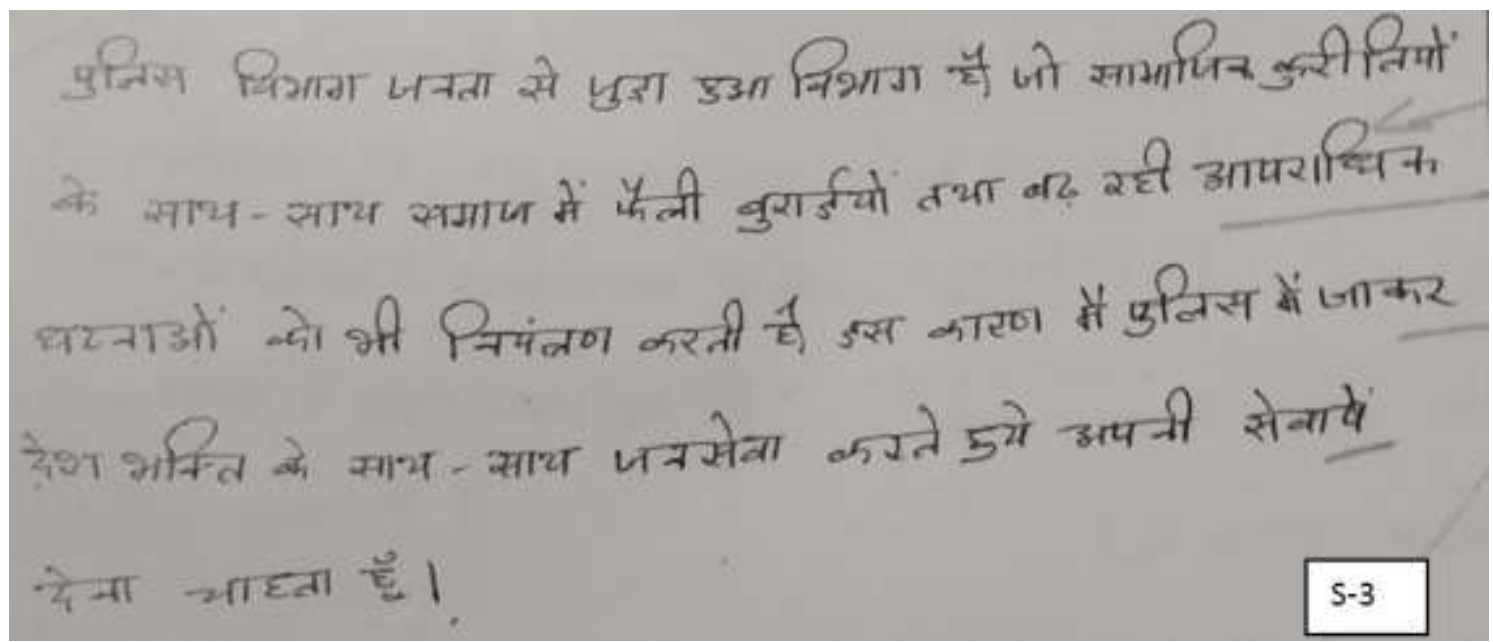

Fig. 5: Specimen Handwriting of Suspect-A marked as S-3

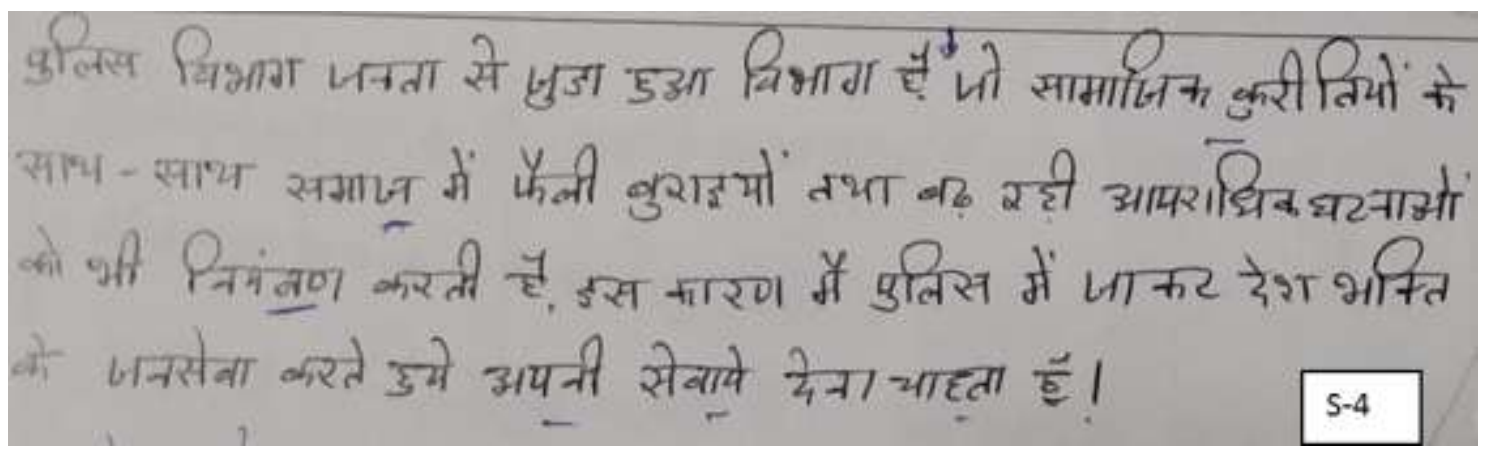

Fig. 6: Specimen Handwriting of Suspect-A marked as S-4

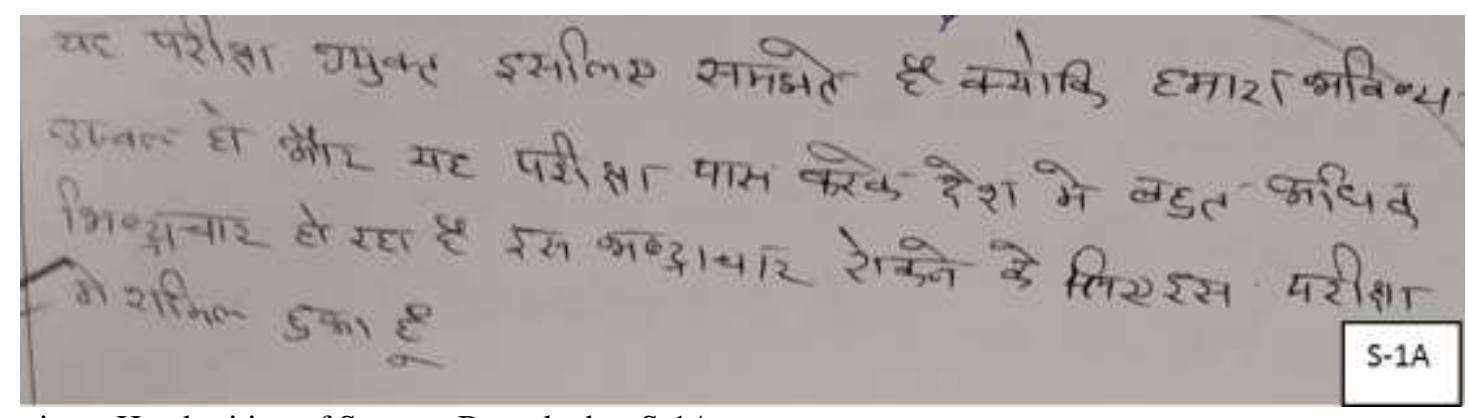

Fig. 7: Specimen Handwriting of Suspect-B marked as S-1A 


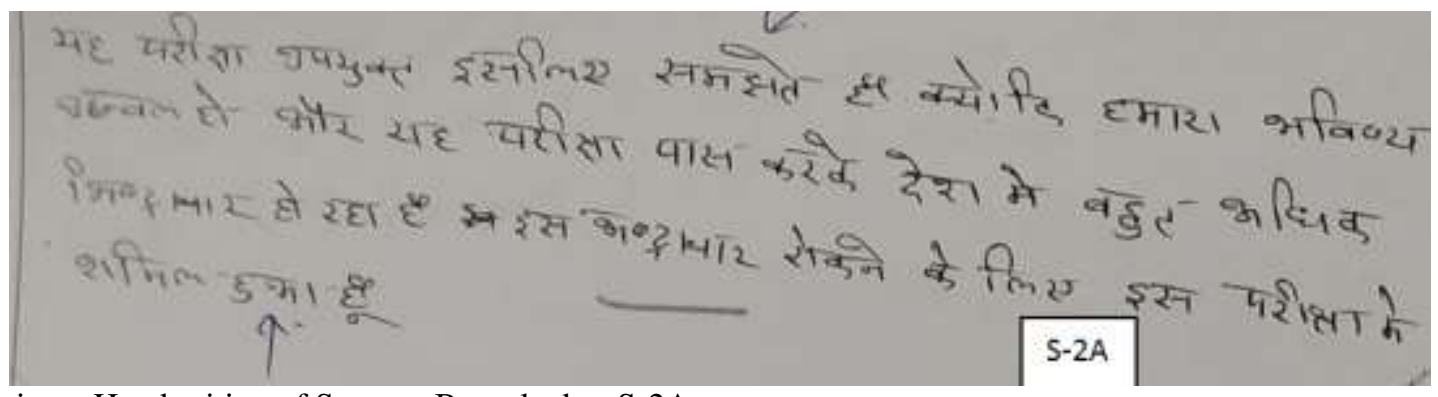

Fig. 8: Specimen Handwriting of Suspect-B marked as S-2A

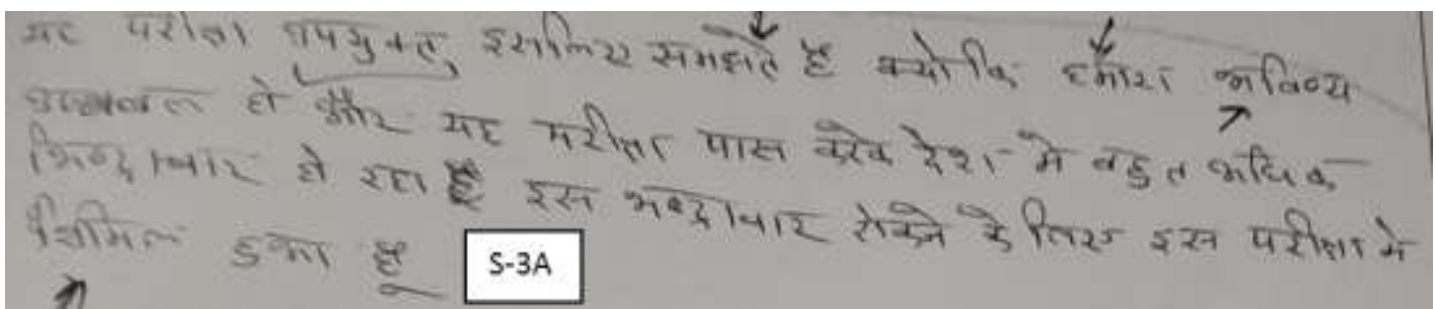

Fig. 9: Specimen Handwriting of Suspect-B marked as S-3A

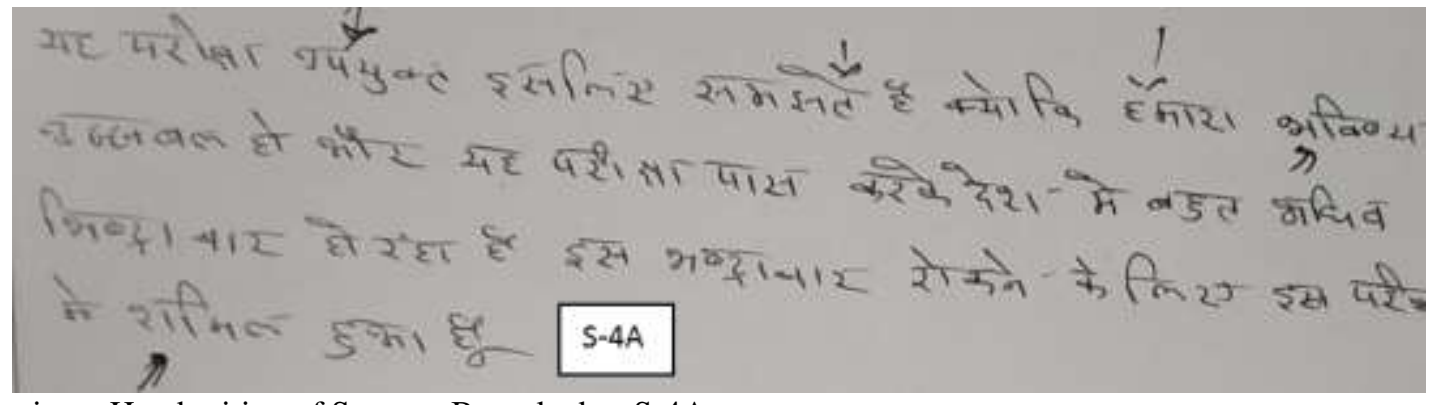

Fig. 10: Specimen Handwriting of Suspect-B marked as S-4A

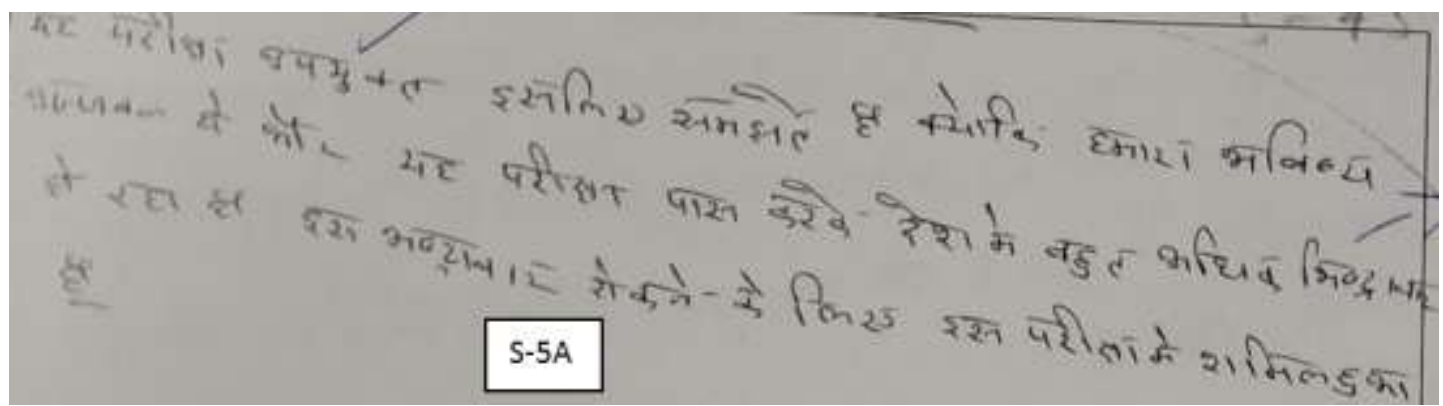

Fig. 11: Specimen Handwriting of Suspect-B marked as S-5A

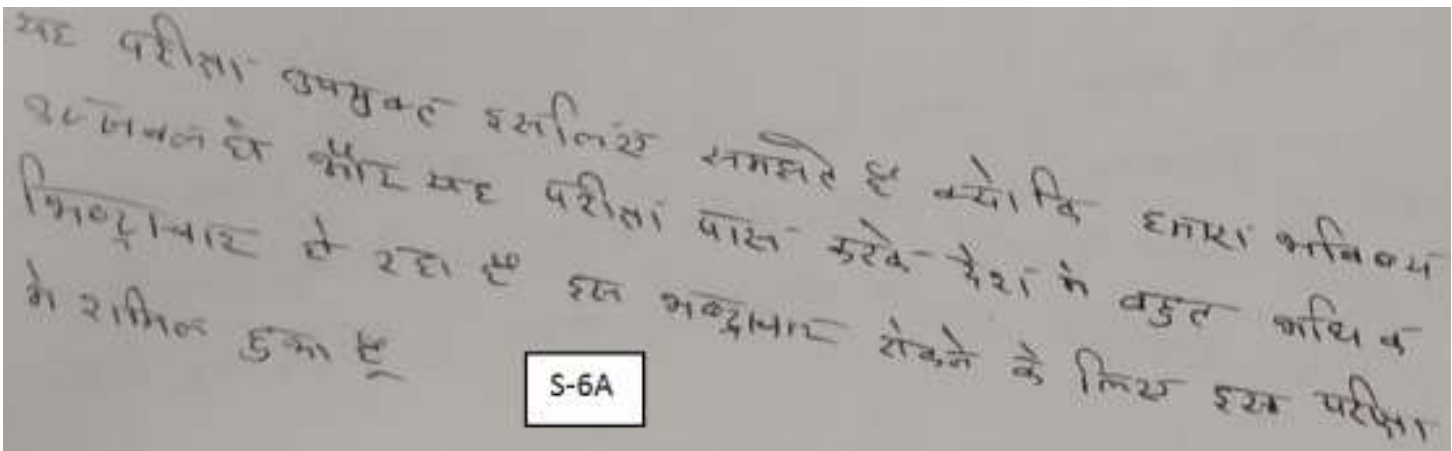

Fig. 12: Specimen Handwriting of Suspect-B marked as S-6A 
The said case was scientifically examined for comparison of questioned handwritten writing of OMR sheet marked as Q-3 shown in Fig. 1 with the specimen writing marked S-1 to S-4 shown in Figure 3 to Fig. 6. During the course of examination it was observed that specimen S-1 to S-4 shown in Figure 3 to Figure 6 was written with free flow with normal writing habit of writer and handwriting content having significant handwriting characteristic features in terms of identifying elements and individual handwriting features in the form of formation of letters as well as their nature of movements of strokes, relative shape, size of individual letters formation, manner of connecting strokes in formation of peculiar Hindi letters such as Aa, ka, $\mathrm{Pa}$, Va, Bha, Ja, Sa, Ta etc. as well as curvatures in strokes while forming letters Ha and its connection with the matra small oo, which were considerable factors for examination as well as comparison with questioned ones and for expression of an opinion. The specimens writing marked S-3 to S-6 were written in normal writing habit of the writer. In these specimens writing, the suspected author was known to his involvement in this particular case. The authorship of handwritings on the questioned original OMR sheet marked Q-3 was fixed with the specimen writings of supplied specimen marked S-1 to S-4 illustrated in Figure 3 to Fig. 6. The handwriting characteristics of both sets of handwriting content were thoroughly examined to account for the questioned handwriting characteristic features with specimen writing characteristics with respect of their range and extent of natural variation. On the basis of cumulative consideration of detailed study of all significant identifying characteristic features of handwriting in execution of various letters and strokes in the letters formation as well as combination of letters in execution of Hindi words such Police, Vibhag, Samaajik, Apradhik, kuritiyon, Niyantrit, SaathhSaathh as observed in questioned handwriting was similarly observed in specimens handwriting which led to the identification of similar authorship, the definite conclusion was drawn to form an opinion and authorship of Suspect A was fixed. Similarly the authorship of suspect B was also fixed with the corresponding specimen handwriting on the basis of significant handwriting characteristic features in peculiar formation of Hindi letter Ksha, Ha, Ma, Bha, Ra, and also in execution of Hindi words such as Ujwal, Bhrashtachaar, Shamil, Hua, Bhavishya etc in between both the sets. The detailed of peculiar characteristics features between questioned handwriting and specimen handwriting of suspected person A and B which were considered as individual identifying characteristic features is illustrated in by arrows in Fig. 1 to Fig. 12.

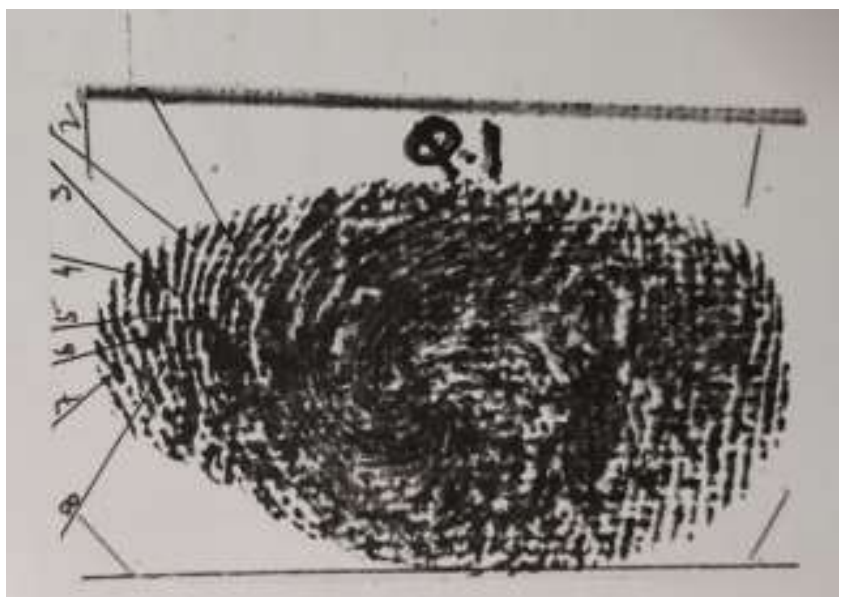

Fig. 13: Showing questioned thumb impression of suspect-A marked as Q-1

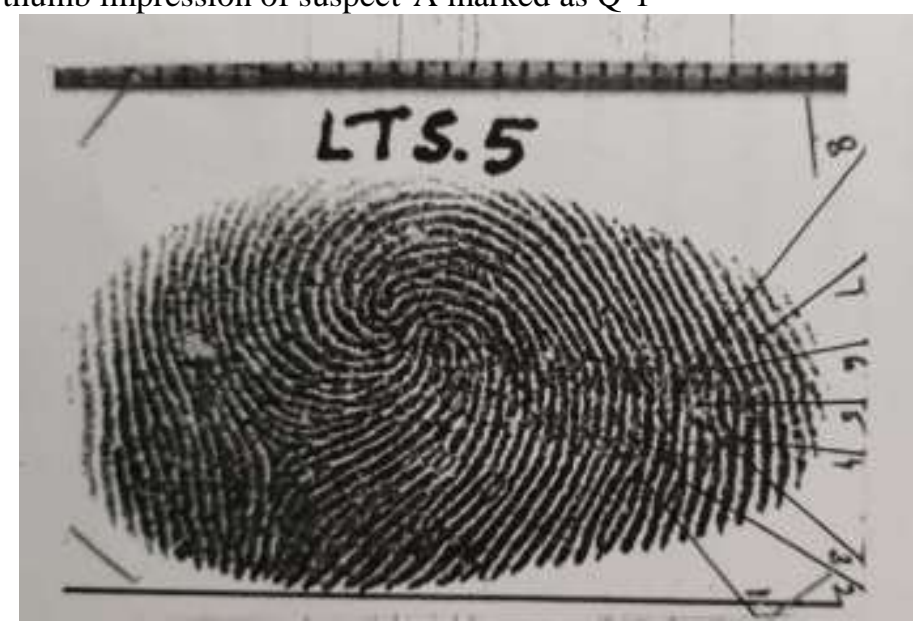

Fig. 14: Showing specimen thumb impression of suspect a marked as LTS-5 


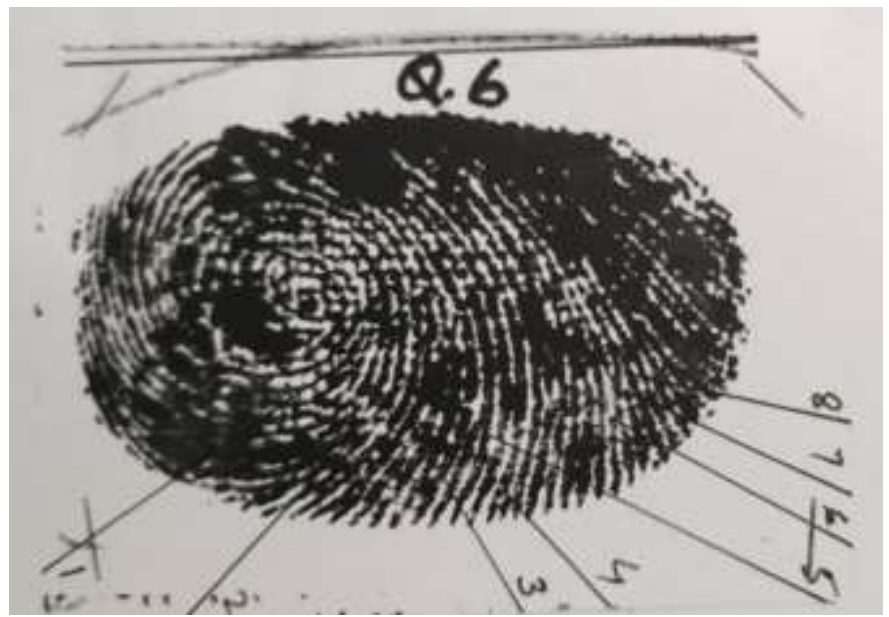

Fig. 15: Showing Questioned Thumb Impression of Suspect B marked as Q-6

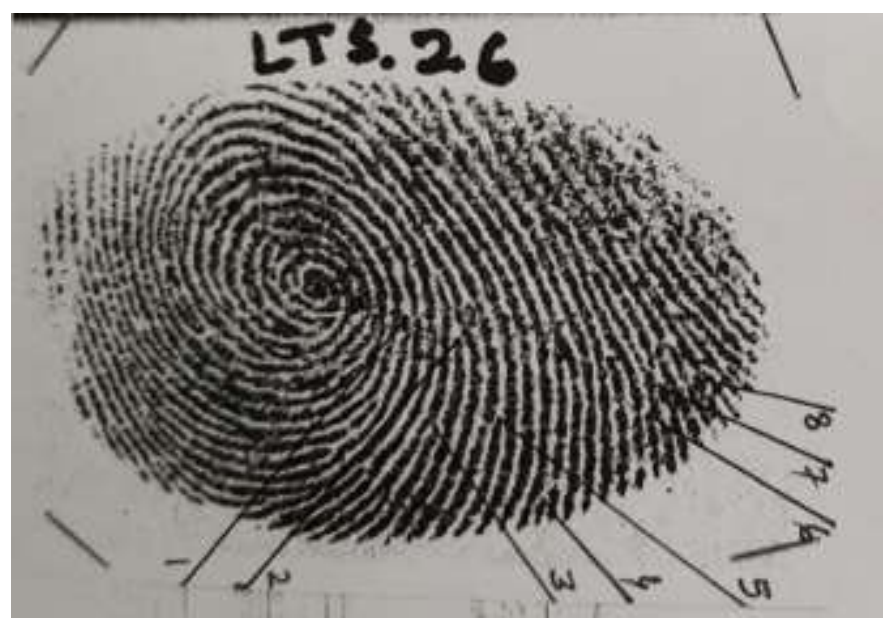

Fig. 16: Showing specimen thumb impression of suspect-B marked as LTS-26

The detail significant similarity in ridge characteristics in between Questioned Thumb Impression and Specimen Thumb Impression is shown in Table 1.

Table 1: Showing the comparison of questioned thumb impression and specimen thumb impression.

\begin{tabular}{|c|c|l|}
\hline $\begin{array}{c}\text { Questioned Thumb } \\
\text { Impression }\end{array}$ & $\begin{array}{c}\text { Specimen Thumb } \\
\text { Impression }\end{array}$ & \multicolumn{1}{|c|}{ Remarks } \\
\hline & $\begin{array}{l}\text { The identical ridge characteristics have been found in their } \\
\text { relative position in both Questioned thumb impression and } \\
\text { specimen thumb impression. } \\
\text { Point No-1 to Point No.8 shown by projected line. } \\
\text { (suspect-A) }\end{array}$ \\
\hline & & $\begin{array}{l}\text { The identical ridge characteristics have been found in their } \\
\text { relative position in both Questioned thumb impression and } \\
\text { specimen thumb impression. } \\
\text { Point No-1 to Point No.8 shown by projected line. } \\
\text { (Suspect-B) }\end{array}$ \\
\hline
\end{tabular}

\section{Results and Discussion}

The case was submitted in central forensic science laboratory CBI New Delhi for examination and opinion on
OMR sheets bearing handwriting and thumb impressions. When the questioned handwriting was compared with the 
supplied specimen handwriting, it was found consistent in the writing characteristic features. Significant consistency in writing characteristic features and formation of letters as well as connection, combination of strokes in execution of letters in word formation of both questioned and specimen handwriting of suspects A and B reveals that the authorship of both questioned and specimen handwriting is same. Examination of Questioned Handwriting marked Q-3 and its comparison with Specimen Handwriting marked S-3 to S-6 revealed that both questioned and standard writing content was written by one and the same person i.e., suspect A. Similarly examination of Questioned Handwriting marked Q-8 and its comparison with Specimen Handwriting marked S-7 to S-12 revealed that both questioned and specimen writing content was written by one and the same person i.e., suspect $\mathrm{B}$. The case is example of one of the scam case related with involvement of impersonator in place of actual person. On the basis of thorough scientific examination applying the principle of handwriting science and figure print science, the authorship was fixed and also scientific evidences produced by the experts suggested that the suspected person was involved in this scam. Result of examination was purely based on the scientific examination of significant individual characteristic features of writer in handwriting content and significant similarity ridges characteristic features in thumb impression. The case was successfully solved and opined by the experts and the forensic evidence was given in court during court testimony. The scientific findings of experts expressed in opinion was based on scientific examination and analysis and accepted in court of law.

\section{Conclusion}

The above mentioned criminal case was examined on the basis of principles of handwriting Science and finger print. Forensic examination reveals that the questioned thumb impression marked as Q-1 was found identical with the Specimen Thumb Impression marked as LTS.5 on the specimen slip of Suspect A. on the basis of scientific examination of ridges characteristics of both Questioned Thumb Impression marked Q-1 and Specimen Thumb Impression marked LTS.5, the opinion was expressed that these thumb impressions are identical. The matching ridge characteristics which was found in their relative positions in the questioned and specimen thumb print shown in Fig. 13 and Fig. 15. The Questioned Thumb Impression marked as Q-6 was found identical with the Specimen Thumb Impression marked as LTS.26 on the specimen slip of Suspect B. on the basis of comparison and scientific examination of ridge characteristics of both Questioned Thumb Impression marked Q-6 and Specimen Thumb Impression marked LTS.26 the opinion was expressed that these thumb impressions are identical. The matching ridge characteristics which was found in their relative positions in the questioned and specimen print shown in Fig. 14 and Fig. 16.

From the illustrated case, it is clear that the role of forensic scientist as an expert is very important so as to produce the proof of evidence in the court of law. This case was a unique one related with the involvement of impersonator, in which the proof of evidence was produced by both Handwriting Science and Finger Print experts. The case is related with the unplanned crime, only for getting employment and the suspect was not aware about the impact of doing such crime. This case is an excellent example of prudent scientific work spirit of both questioned document expert as well as finger print expert in solving criminal case. The definite opinion furnished by both forensic document expert as well as finger print expert was accepted in the court of law and the suspected person was convicted. This is a best example of the role of forensic experts in solving cases in assisting criminal justice system. On the basis of opinion expressed by the forensic experts, the case was successfully solved and criminals were convicted.

\section{Conflict of Interest: None.}

\section{References}

1. Questioned Document. Albert S. Osborn. Nelson-Hall Co., Chicago, III.,1929.

2. Harrison, W. R. "Suspect documents- their scientific examination", Nelson-Hall.1958

3. Hardless, HR. "Disputed documents examination \& fingerprint identification", Law book company. 1970.

4. Conway, JVP., "Evidential documents", Chales C Thomas publisher ltd.1978.

5. Ordway Hilton Scientific Examination of Questioned Document, Revised Edition, CRC Press.1993.

6. Wilson R Harrison, Suspected Document: Their Scientific Examination, second Indian Reprint, Universal Law Publishing Co. Pvt. Ltd.1997.

7. Huber, R. A. \& Headrick, A. M. "Handwriting identificationfacts and fundamentals", CRC Press LLC. 1999

8. Morris, R. N, "Forensic handwriting identification: fundamental concepts and principles", Academic Press. 2000

9. Ellen, D. "Scientific examination of documents- methods and techniques", 3rd edition, CRC Press- Taylor \& Francis group. 2006.

10. Kelly, JS. \& Lindblom, BS. "Scientific examination of questioned documents", CRC PressTaylor \& Francis group. 2006

11. Koppenhaver, KM. "Forensic document examinationprinciples and practice", Humana Press Inc.2007.

12. Eric H Holder Jr, Laurie O Robinson, John H. Laub. "The Fingerprint Source Book" U.S Department of Justice, Washington DC, National Institute of Justice.

How to cite this article: Gupta RR, Prasad H, Forensic examination of handwriting and thumb impression-A case study. Int J Forensic Med Toxicol Sci 2019;4(2):42-8. 